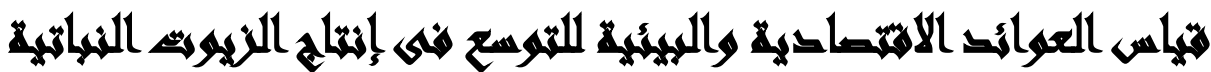

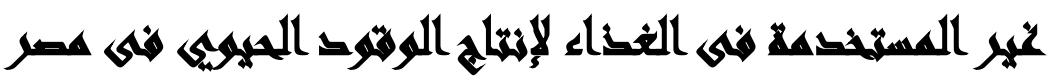
[iv]

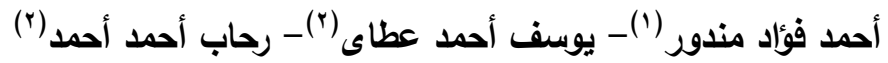

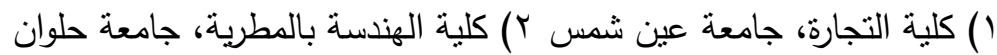

\section{الممتخلس}

تُعتبر الطاقة عنصر أساسى لتحقيق تتمية إقتصادية ولكن المصدر التقلقيدى المُهيمن

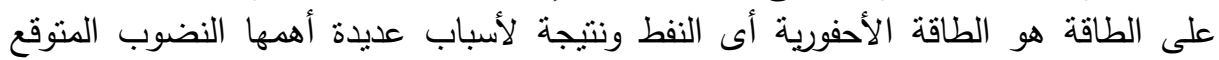

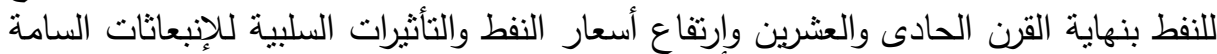

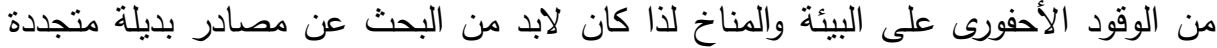

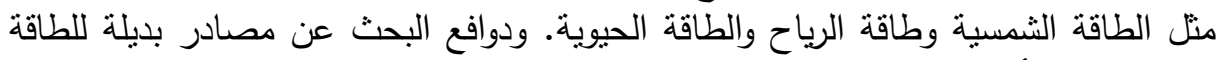

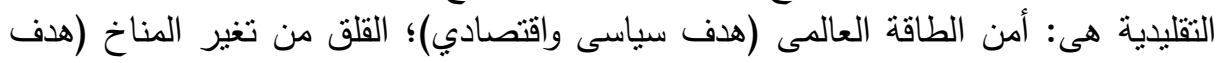
بيئى)؛ إنخفاض نكلفة الطاقات المتجددة (هدف اقتصادي)؛ دعم المنتجين الزراعيين (هدف

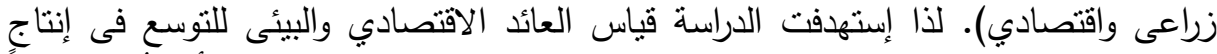

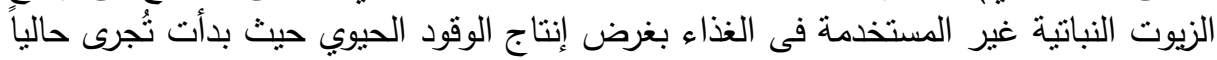

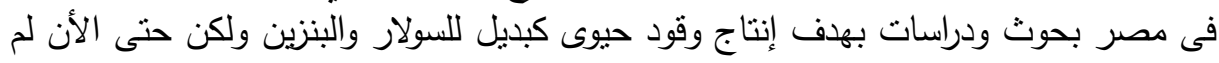

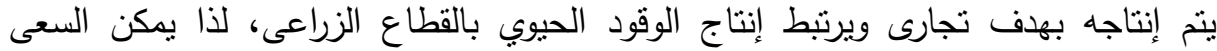

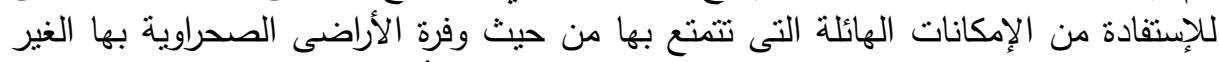

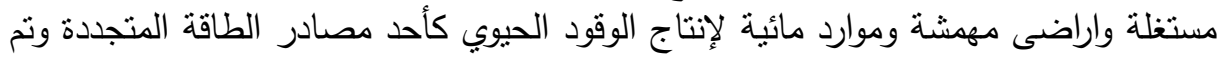

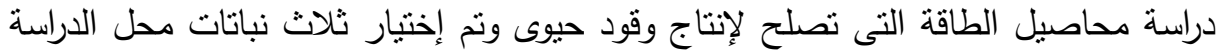

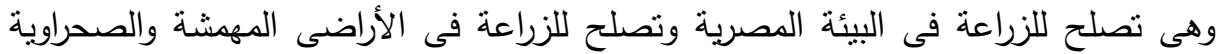

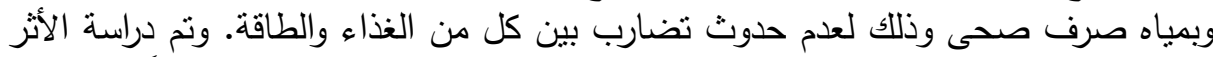

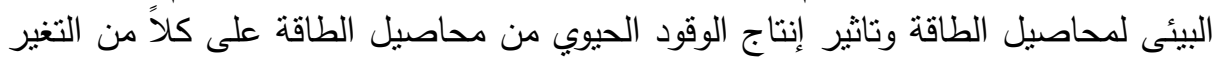

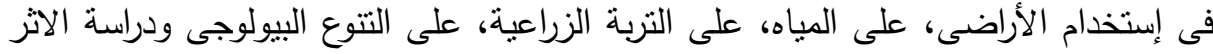

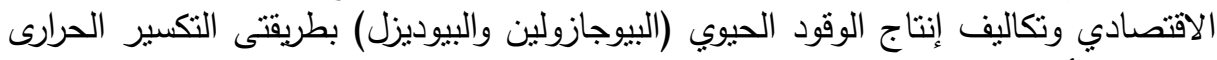

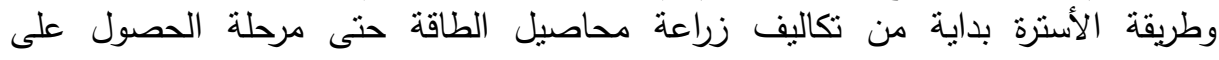
البيوجازولين والبيوديزل.

$$
\text { المجلد الحادي والأربعون، الجزء الثالث، مارس 11 إ. }
$$


ولتحقيق أهداف الدراسة تم إنباع المنهج الوصفى التحليلى حيث قام الباحثون بالدراسة

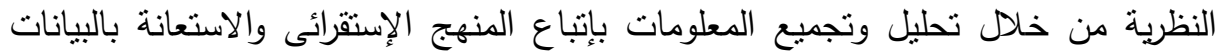
الإحصائية والمعلومات المطبوعة والمنشورة فى الدوريات والمجلات المحلية الماعلية والدولية والدراسة

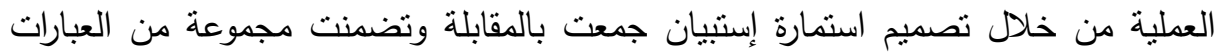

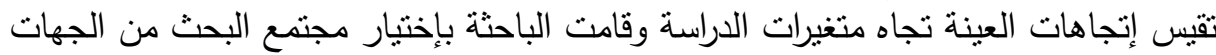

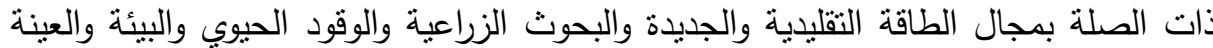

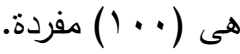

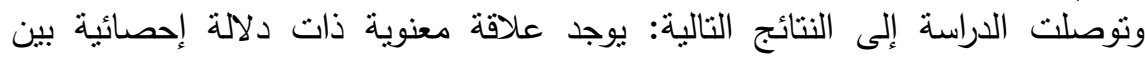

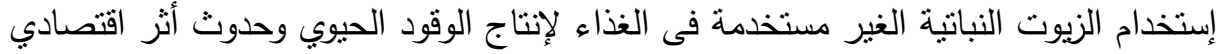

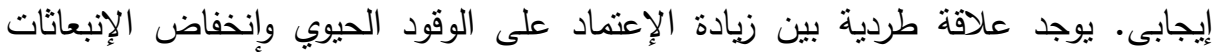

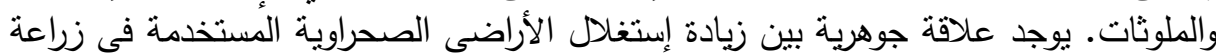

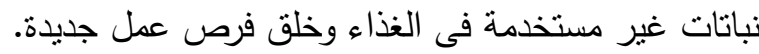

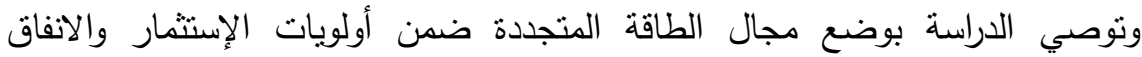

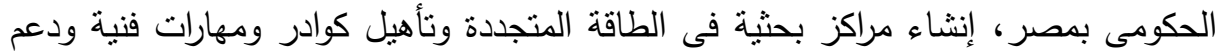

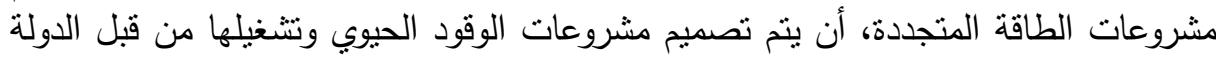
وان يشارك فيها جميع أصحاب المندة المصلحة. الكلمات الدالة: الطاقة المتجددة، الوقود الحيوي، التتمية المستدامة.

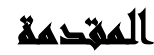

تعتبر الطاقة عنصر رئيسى فى عملية النمو الاقتصادي لأى بلد وتوافر مصادر الطاقة

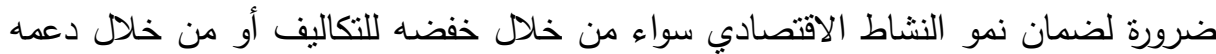

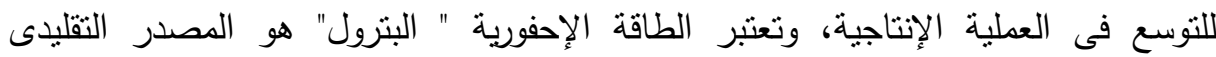
لمصادر الطاقة ويتزايد استهلالك الطاقة بسبب زيادة عدد السكان ونمو الصناعة عالمياُ ونظراً لأن البترول مصدر غير متجدد ولحدوث إرتفاع فى اسعار الطاقة بالإضافة إلى أثنره على ولى البيئة حيث يؤدى لزيادة التلوث البيئى من خلال إنبعاث الغازات المسببة للاحتباس الحرارى، حث ذللك واضعى السياسات وصناع القرار لضرورة إيجاد مصادر أخرى بديلة ومتجددة للنفط تتميز بالإستدامة وتقلل من التأثنرات السلبية للإنبعاثات السامة من الوقود الأحفورى على البيئة والمناخ وتتمنل أهم المصادر البديلة فى الطاقة الثمسية وطاقة الرياح والطاقة الحيوية. وسنتأول الوقود الحيوي كأحد مصادر الطاقة البديلة المتجددة. 
الوقود الحيوي هو الطاقة المستمدة من المادة العضوية للكائنات الحية وتستخدم كبديل للوقود الأحفورى وهى عبارة عن تحويل الكتلة الحيوية "مادة ذات أصل طبيعى" سواء نباتى أو لون حيوانى إلى طاقة متجددة لأنها تحول طاقة الثمس إلى طاقة مُخزنة فى النبات عن طريق التثثيل الضوئى (محمد طالبى، مجلة الباحث، 7 ج . . ب). وهناك ثلاث أنواع للوقود الحيوي: غازى أو صلب أو سائل ويعد الوقود الحيوي السائل من أفضل أنواع الوقود إذ يسهل نقله بالأنابيب وتخزينه ويُستخدم فى محركات وسائل النقل

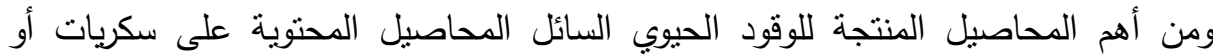
نشويات كالذرة وقصب السكر وأهم أنواع الوقود الحيوي السائل هو الإيثانول الحيوي والديزل

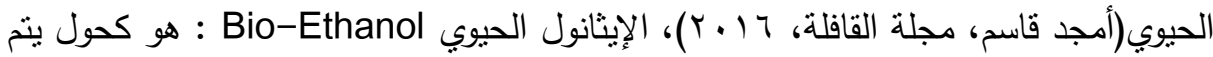
إنتاجه عن طريق تخمير السكر أو النشا الناتج من محصول قصب السكر أو الذرة وتعتمد الولايات المتحدة على الذره فى إنتاجه بينما الديزل الحيوي Biodiesel : هو سائل اصفر لهربئ اللون قابل للتحلل غير سام ويطلق إنبعاثات أقل بكثير عن تلك التى يطلقها الديزل النفطى،

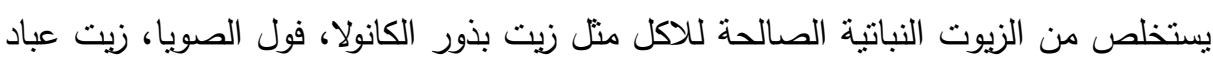

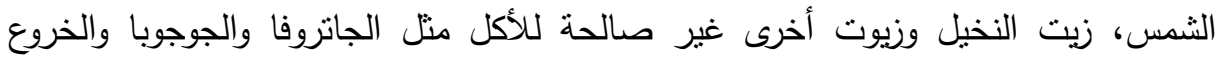
(رانيا محمود شكرى، Y 1 (Y) كذللك يمكن إستخدام زيوت الطهى المعاد تدويرها ويتم إنتاجه بطريقتى التكسير الحرارى أو الأسترة لانتاج البيوجازولين كبديل للبنزين أو البيوديزل بديل لبديل

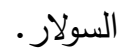

\section{xasty}

تتمثل مشكلة البحث فى مدى إمكانية التوسع فى إنتاج الزيوت النباتية الغير مستخدمة فى الغذاء لإنتاج الوقود الحيوي، وذلك نظراً لتوقع نضوب البترول بالإضافة للتلوث البيئى

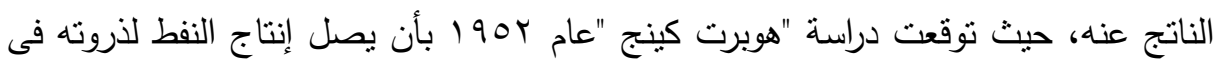

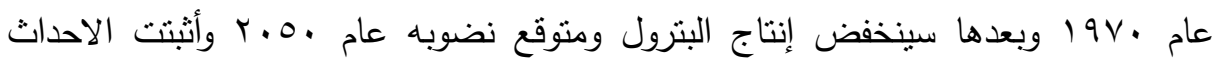
صدق نظريته حيث بلغ إنتاج النفط ذروته فى عام • 19V بعدها بدا فى الانخفاض، لذا

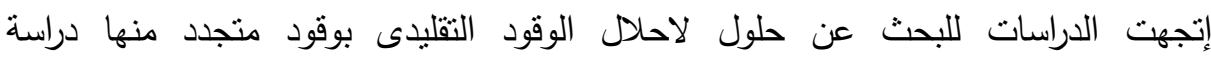

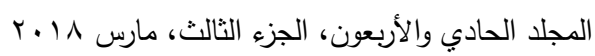




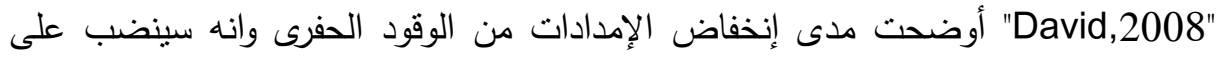

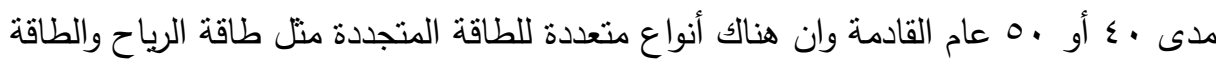

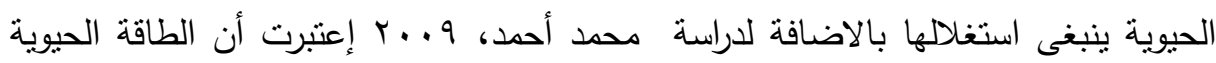

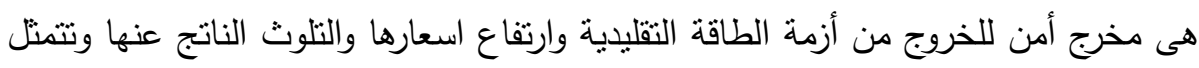
مشكلة الدراسة فى مدى إمكانية التوسع فى إنتاج الزيوت النباتية غير المستخدمة فى الغذاء الثهاء لإنتاج وقود حيوى (بديل للبنزين والسولار ) وإحلاله محل الوقود الاحفورى والاستفادة من مياه الصرف الصحى المعالجة وخلق فرص عمل وإستغلال مساحات واسعة من الرقعة الصحراوية

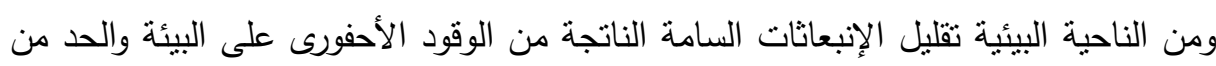

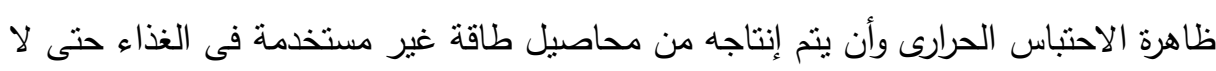

$$
\text { تتنافس مع الغذاء (الجوجوبا والجاتروفا والخروع). }
$$

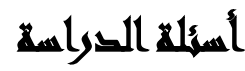

• ما إمكانية إحلال الوقود الحيوي بوقود تقليدى (بنزين وسولار)؟

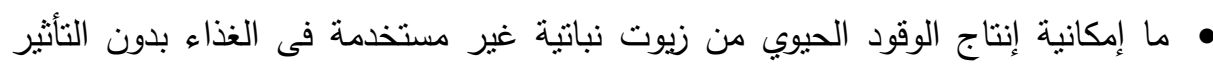

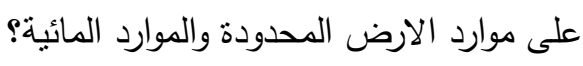
• ما إمكانية إستغلال مساحات الأراضى المهيشة ومياه الصرف الصحودى الصحى المعالجة لزراعة نباتات غير مأكولة تصلح لانتاج وقود حيوى؟ إنغانه

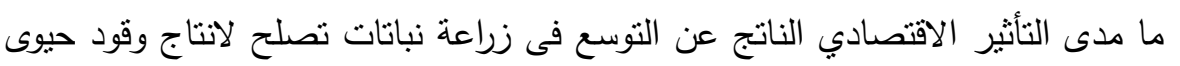

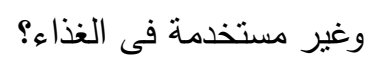
• هل هناك عائد بيئى ناتج عن إستبدال الوقود التقليدى بوقود حيوى؟

\section{الهساهي القراسلة}

تهذف الدراسة إلى تقييم العائد الاقتصادي والبيئى للتوسع فى إنتاج الوقود الحيوي المنتج

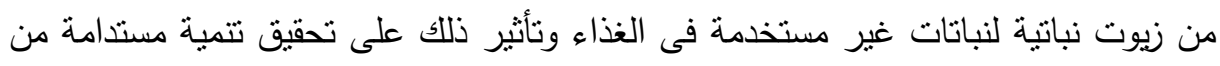

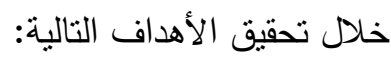


أحمد فؤاد مندور وآخرون

• التعرف على أنواع الزيوت النباتية المستخدمة فى إنتاج الوقود الحيوي.

• دراسة العائد البيئى الناتج عن إنتاج الوقود الحيوي.

• تقييم العائد الاقتصادي للتوسع فى إنتاج الزيوت النباتية الغير مأكوله لإنتاج الوقود

الحيوي.

\section{أهميد التواسمة}

يعتبر الوقود الأحفورى هو المصدر المهيمن على مصادر الطاقة فى العالم ومن المتوقع نضوبه فى نهاية القرن الحادى والعشرين، لذا توجه اهتمام الدول للبحث عن مصادر بديلة للطاقة وتدعم عملية التتمية المستدامة ومنها الوقود الحيوي. لذا اهتمت الدراسة ببحث أزمة الطاقة التقليدية (الوقود الأحفورى) ودراسة أنواع الوقود الحيوي والمحاصيل الزراعية التى تستخدم فى إنتاج الوقود الحيوي وتأثيرها على ارتفاع أسعار السلع الغذائية، وتقييم التأثثر الاقتصادي والبيئى لاستبدال الوقود الحيوي بالوقود التقليدى، والتوسع فى إنتاج الزيوت النباتية الغير مستخدمة فى الغذاء لانتاج الوقود الحيوي بغرض تحقيق التنمية المستدامة.

\section{الضواسماهت المساوهية}

تم التمييز بين الدراسات العربية والدراسات الأجنبية للتقريب بين الفكر العربي والفكر الأجنبي الذي يعاني من نفس المشكلات وكيفية تتاولها.

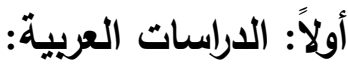

فاتح بن نونة (10 ب ب): توصل الباحث إلى أن تتمية إنتاج الوقود الحيوي فى الولايات

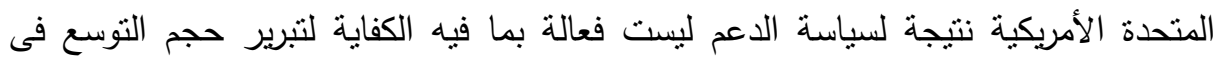
إنتاج الإيثانول المستخرج من الذرة فى الولايات المتحدة الأمريكية لذا فإن التوجه لإنها لإحلاد الايثانول كوقود بديل للنفطى هدفه الرئيسى أمن الطاقة وليس لأسباب إقتصادية أو بيئية بحتة الإنة

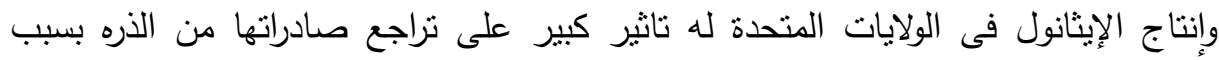

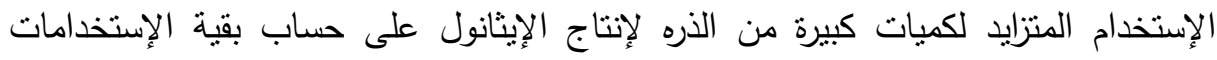

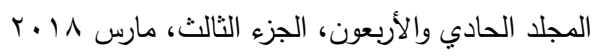


الاخرى ولم يمتد آثار إنتاج الإيثانول على سوق الذره بل إمتد لأسواق وأسعار الحبوب الأخرى من خلال اثر الإحلال أوإعادة تخصيص موارد الإنتاج الزراعى. الإبالي.

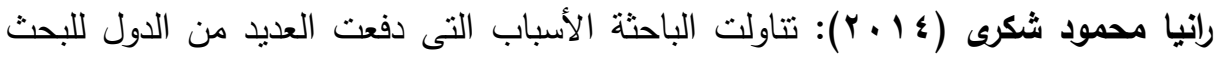

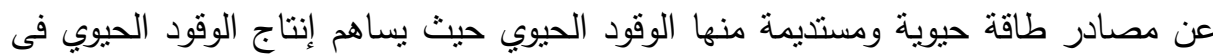

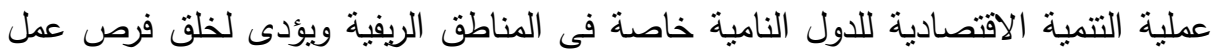
من خلال صناعات جديدة وجذب المزيد من الإستمارات وبالنسبة لمصر وضعت إستراتيجية لتتويع مصادر الطاقة وترشيد إستهلاكها ومن احد مصادر الطاقة هى الطاقة الحيوية وهناك مجموعة عناصر هامة لنجاح هذه الصناعة فى مصر وهى العمالة منخفضة التكاليف والاراضى الصحراوية والقدرة على إستصلاحها وريها بمياه الصرف الصحى المعالجة والمناخ المناسب والموقع الجغرافى المتميز وإنتاجها من محاصيل غير غذائية كالجاتروفا والجوجوبا. وتوصلت الباحثة إلى أن السعر المنخفض للوقود السائد فى السوق المحلى فى الوقت الحالي رغم رفع الدعم جزئياً عليه يحد من نمو صناعة الوقود الحيوي المصرى رغم وجود فرص هائلة لإنتاجه من الجاتروفا والجوجوبا لكن يمكن لهذه الصناعة أن تستقيد من سوق الوقود الحيوي المتتامى بشكل كبير فى الإتحاد الأوروبى وتتمو هذه الصناعة كسلعة تصديرية

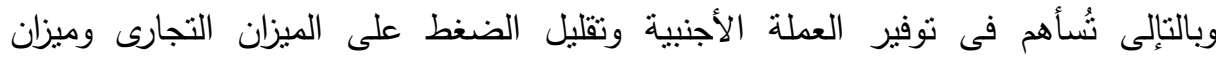
المدفوعات ويُساعد فى ذلك موقع مصر الجغرافى وقربها من الإتحاد الأوروبى وتتمو هذئه الصناعة فى مصر كسلعة تصديرية بما يساهم فى توفير العُملة الأجنبية ونمو هذه الصناعة الأني

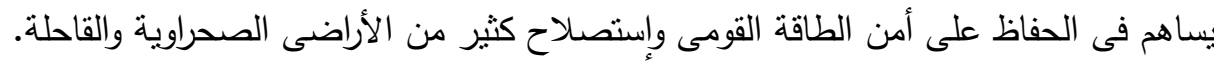

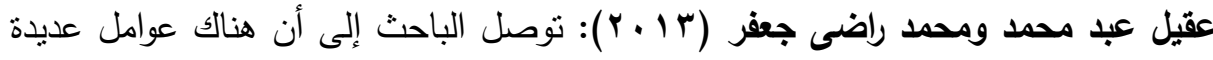
(ارتفاع أسعار الطاقة، وهيمنة بلدان الثرق الأوسط على أغلب الثمل احتياطى مصادر الطاقة

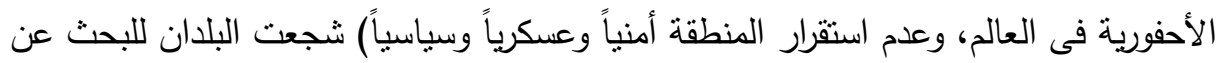

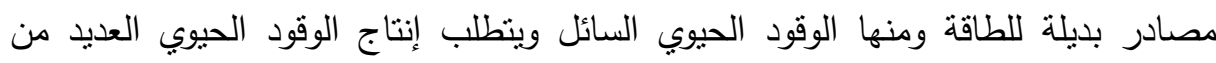
الاحتباجات مثل المواد الزراعية اللازمة لانتاجه والتى ستتعكس فى تزايد أسعار المواد الغذائية

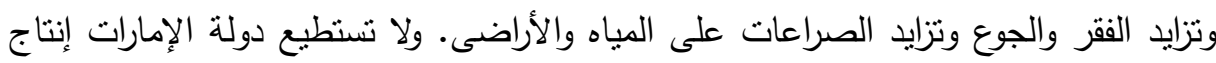


الوقود الحيوي السائل على الأقل فى الددى القريب والمتوسط لعدم توفر مقومات ومستلزمات إنتاج محاصيل إنتاجه سواء من مياه أو أراضى زراعية، لذا من الافضل لدولة الإمارات إنتاج

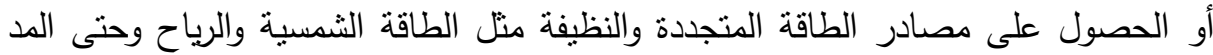

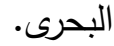

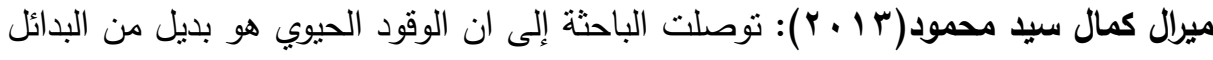

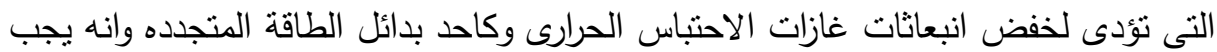
انتاجه من مواد أو سلع لا تؤثر على غذاء الانسان فيما يعرف بالجيل الثانى للوقود الحيوي لهاب

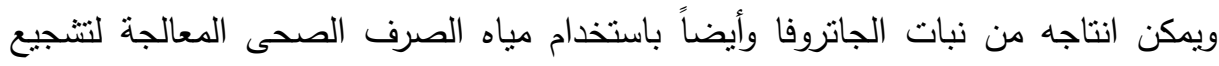
استغلالها فى الاغراض التى تتتاسب نوعيتها للحد من تلوث مياه النيل أو المياه الجوفيه ومن فوائد الجاتروفا انها تساعد على حماية مناطق الاستصلاح من زحف الرمال باتباع الوسائل

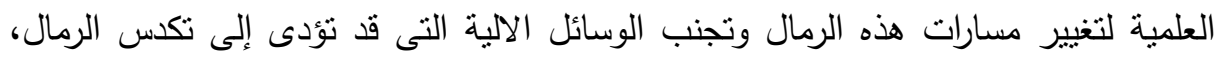

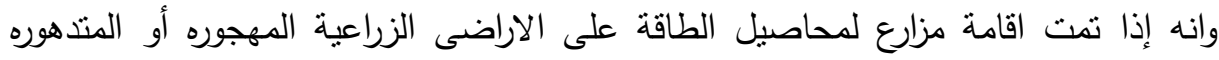
يمكن ان تتخفض مستويات تآكل التربة بسبب الزياده فى غطاء التربه حيث تساعد الجاتروفا على موازنة التربة وتخزين الرطوبه اثثاء نموها.

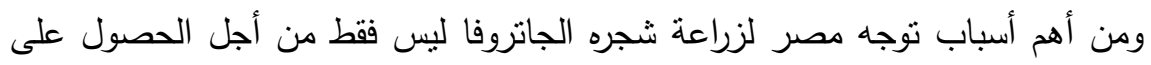

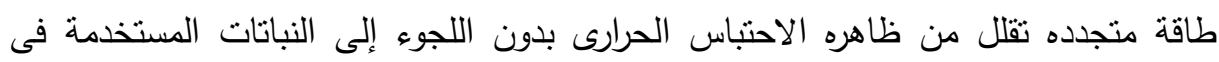
الغذاء وانما أيضاً بهدف استصلاح الاراضى الصحراوية بدون الحاجة لكميات وفيره من المياه كحل نحو تحقيق اكتفاء ذاتى غذائى وزراعى يقبل المنافسة العالمية.

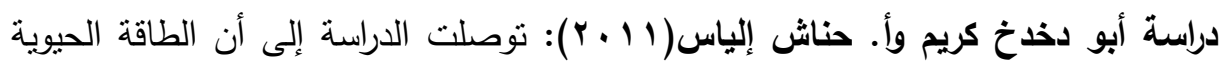

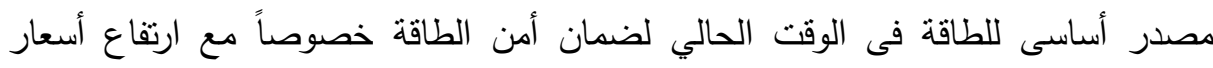

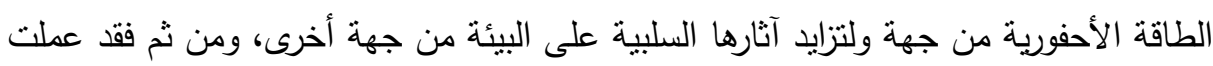
العديد من الدول على زيادة وتطوير قدراتها فى إنتاج الوقود الحيوي المستعمل فى عملية النقل

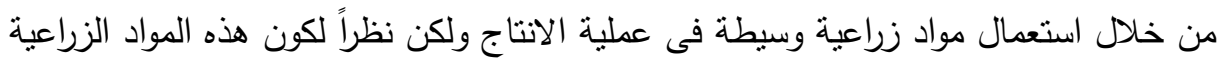

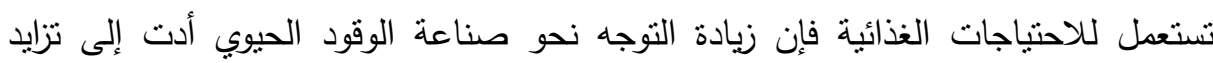

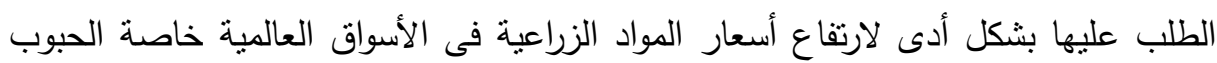

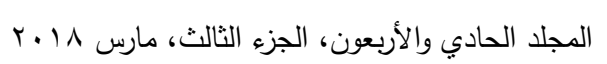


بأثكالها المتعددة والسكر حيث قدرت نسبة مسأهمته فى ارتفاع المؤشر العام لأسعار المواد

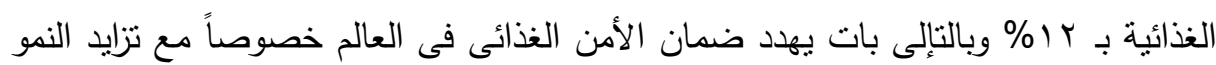

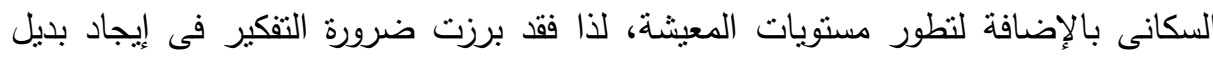

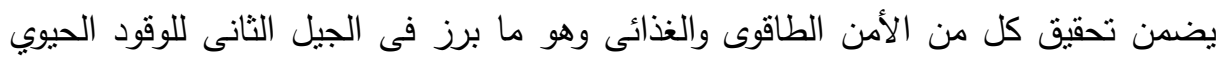
السائل وهو الاعتماد على المحاصيل الغير غذائية والمخلفات الحيوية (القش والأخشاب).

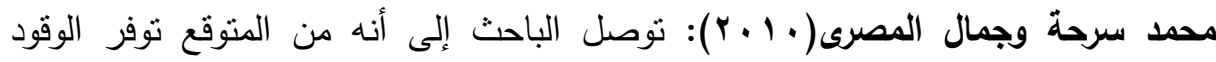

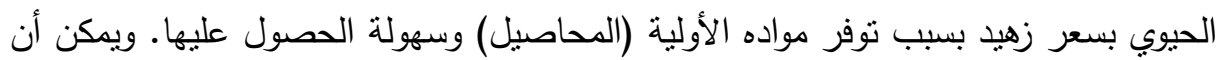

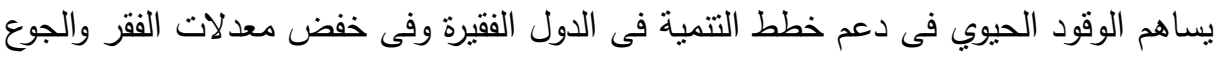

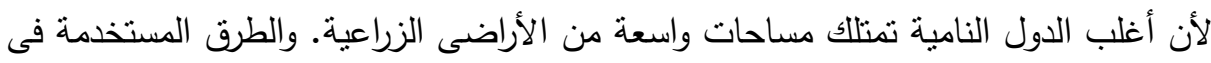
الوقت الحالي لا تجعلنا نحصل على الوقود الحيوي بشكل اقتصادي بالإضافة لاحتباجها للوصول لصفات جديدة نزيد من إنتاجها للطاقة، كما يتعين الاهتمام بدراسة الجوانب الاجتماعية والاقتصادية مثل إدارة المزرعة واختيار مصدر الكتل النباتية بحيث لا يعود إنتاج الوقود الحيوي بالسلب على توفير الغذاء والحفاظ على النتوع البيولوجى، ومن المهم أيضاً التوصل لطرق لتشخيص التأثير البيئى للوقود الحيوي عند احتراقه وانبعاثه فى البيئة ومعرفة

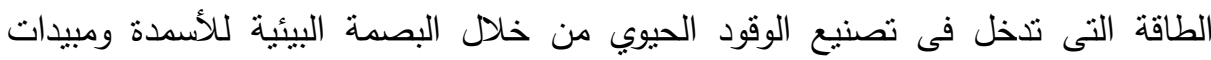
الحشائش المستخدمة فى إنتاج محاصيل الطاقة.

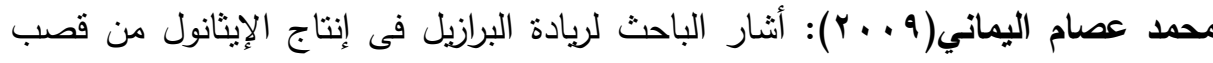

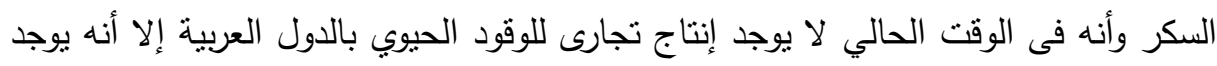

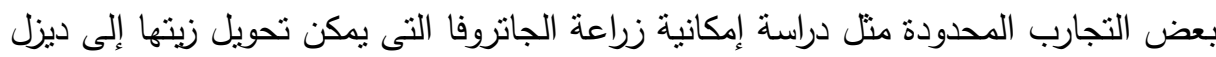
حيوى. توصل الباحث إلى أنه ينبغى دراسة تجارب الدول التى سبقتنا فى إنتاج الوقود الحيوي

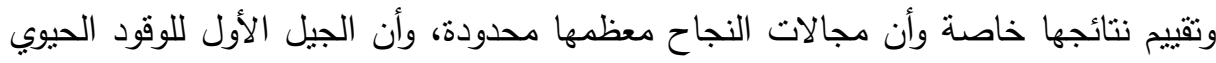
(المنتج من محاصيل نباتية مستخدمة فى غذاء الإنسان والحيوان) تعتبر غير مقبولة نتيجة 
لآثارها الاقتصادية والبيئية والاجتماعية، ولذا كان لابد أن تتوجه الأبحاث نحو الجيل الثانى للوقود الحيوي (المنتج من الأعثاب والسليلوز والطحالب). ثانياً: الاراسات الأجنبية: دراسة A.E. Atabani \& A.S. Silitonga (r ا • ץ): تتاولت الدراسة الزيوت النباتية غير المأكولة التى يمكن إنتاج الديزل الحيوي منها فهى لا تصلح للأغذية البشرية لوجود

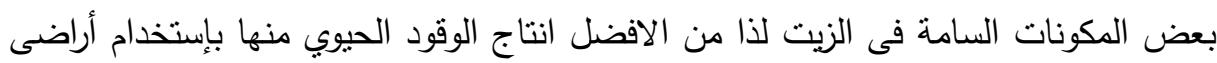

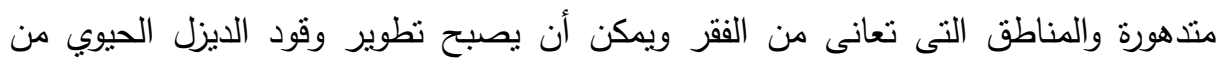
النباتات غير المأكوله برنامج رئيسى للتخفيف من الفقر بالإضافة لأمن الطاقة والارتقاء بالقطاع الريفى غير الزراعى وتتكيف هذه النباتات بشكل جيد مع الظروف القاحلة وغير القاحلة ولاتتافس مع الغذاء ويمكن أن يُشتفاد بما يتبقى منها فى تسميد التربة.

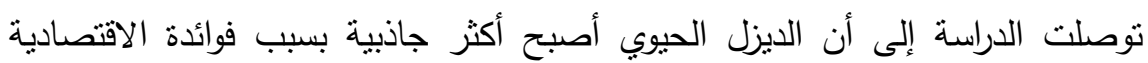

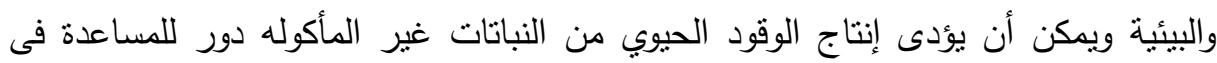
التغلب على مشكلة الأراضى لأنه يمكن زراعتها فى الأراضى الهاهشية بالإضافة إلى إنى ان

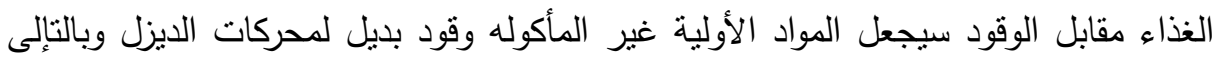

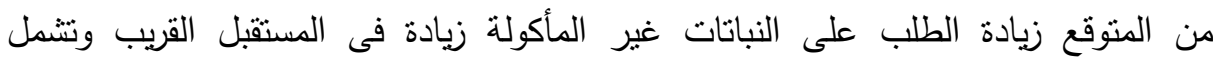

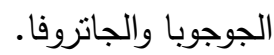
دراسة Amit Kumar Jain , Amit Suhane (r ( • ץ): توصلت الدراسة إلى أن نتيجة تزايد المخأوف من التلوث البيئى وتضاؤل احتياطيات النفط جذب الانتباه نحو استخدام الزيوت النباتية الغير مأكولة كبديل للوقود الأحفورى، حيث تحتوى الزيوت النباتية الغير

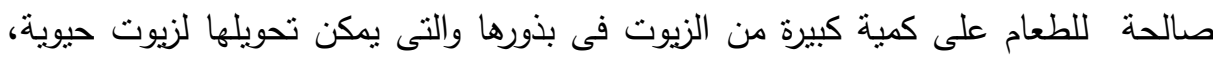
وهى زيوت متجددة قابلة للتحلل غير سامة ولا يصدر عنها غازات نسبب احتباس حرارى،

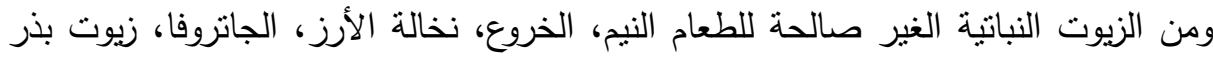


وتقدم هذه الزيوت أداء أفضل أو على الأقل نفس أداء المنتجات النفطية إلى جانب أنها

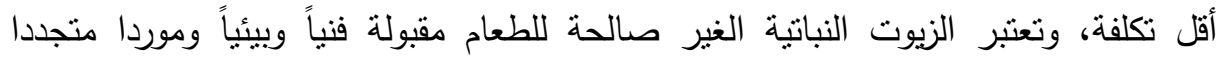
ومتاحا بسهولة، والميزة الأساسية لزيوت الوقود الحيوي تكمن فى قدرتها على الإحلال محل

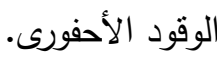
والزيوت النباتية الغير صالحة للطعام هى مصدر واعد كوقود حيوى نظراً لخصائصها التى يمكن مقارنتها مع منتجات النفط القائمة، وهناك حاجة عأجلة للاستكثاف الكامل للزيوت

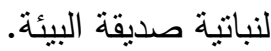
دراسة Khandelwal Shikha and Chauhan. Y. Rita (Y 1 ( ب ): توصلت الدراسة إلى أن أسعار المواد البترولية هى سبب لطلب الوقود الحيوي وهناك حاجة لتكلفة منخفضة

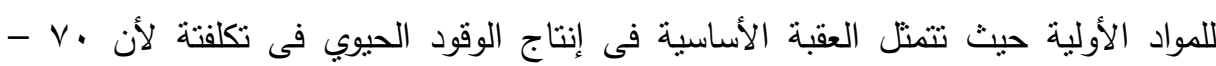

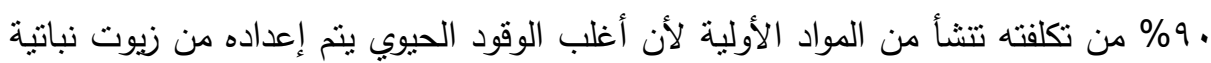

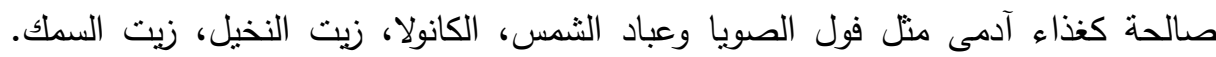

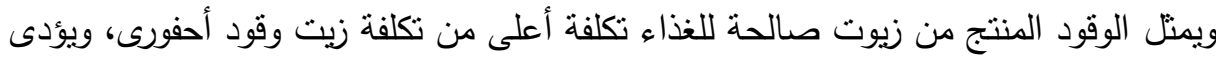
لقضية الغذاء مقابل النفط ويمكن حل المشكلة باستخدام زيوت نباتية غير صالحة للغذاء

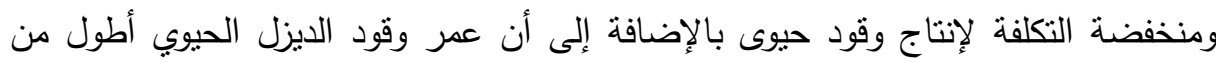
وقود الديزل الأحفورى بسبب التركيبة الدهنية للإسترات الموجودة فى وقود الديزل الحيوي.

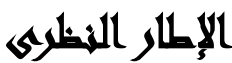

تعد الطاقة هى الخيط الذهبى الذى يربط النمو الاقتصادي والعدالة الاجتماعية

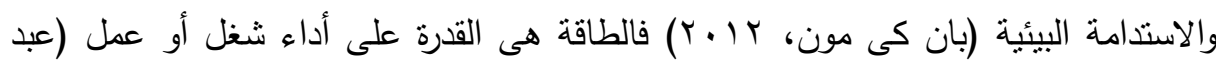

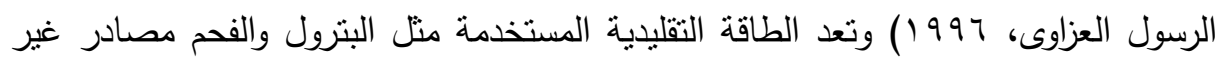
متجددة أى أنها معرضه للنضوب ولا تتجدد لذا اتجهت الانظار لمصادر طاقة بديلة متجددة هى الطاقة المستمدة من الموارد الطبيعية التى تتجدد ومصادرها تختلف عن الوقود الأحفورى

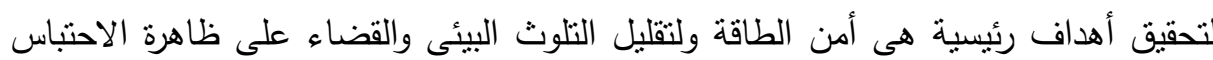

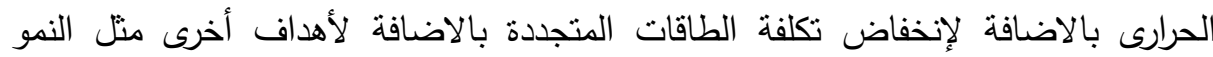

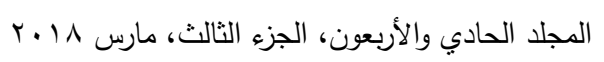


السريع فى الطلب على الطاقة ووجود حقول نفطية فى مناطق غير مستقرة سياسياً وبالتإلى إعتمدت العديد من الدول على سياسات لنتجيع إنتاج الوقود الحيوي (تريكى عبد الرؤوف،

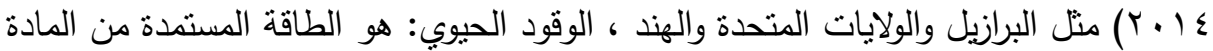
العضوية للكائنات الحية وهى عبارة عن تحويل الكتلة الحيوية إلى طاقة أى تحويل الطاقة

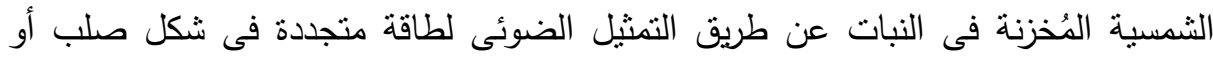

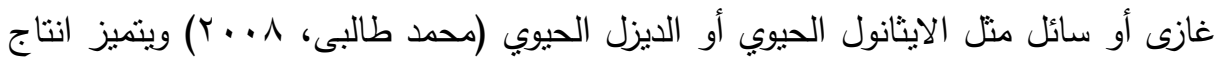
الوقود الحيوي عن غيره من الطاقات المتجددة بعدم تقيده بأى عوامل جغرافية أو طبيعية

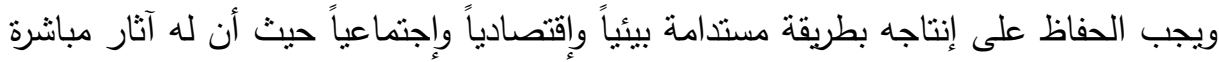
وغير مباشرة على المناخ والتغير فى إستخدام الأراضى والمياه والتربة والتتوع البيولوجى. وينتج الوقود الحيوي من السائل انواع عديدة من المحاصيل الزراعية الوسيطة منل بذور اللفت وزيت النخيل وزيت فول الصويا وزهرة عباد الثمس وزيت الفول السودانى ولكن هذه المحاصيل تستخدم فى مجال الغذاء ولكن حتى لايحدث تضارب بين كلاً من الغذاء والطاقة لذا يجب النظر لإمكانية الاستثمار فى إنتاج الوقود الحيوي وهناك عدد من المعايير التى يجب أخدها

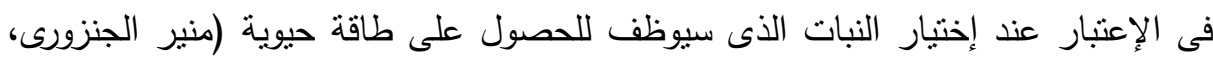

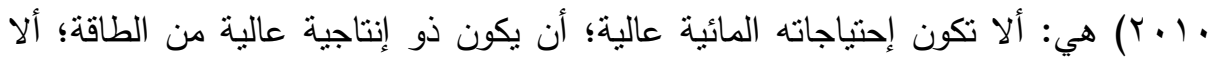

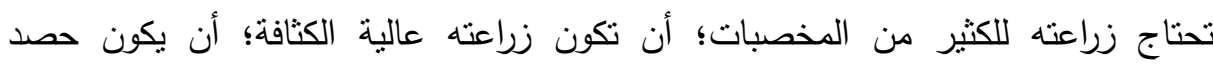
المحصول سهل؛ أن يقاوم الجفاف؛ أن يوظف المواد الغذائية المتاحة له بشكل جيد؛ أن يقاوم مُسببات الأمراض. 
مجلة العلوم البيئية

معهد الدراسات والبحوث البيئية - جامعة عين شمس ليه

وفيما يلى بيان بالمحاصيل الزيتية وعائد الزيت لكل منها.

\begin{tabular}{|c|c|c|}
\hline عائد الزيت (لتر/هكتار/سنوياً) & محتوى الزيت (\%) & مواد أولية \\
\hline $1 \leq 11$ & $\% \circ r$ & Castor \\
\hline 1194 & $\% \varepsilon \cdot:$ ro & Jatropha \\
\hline$\varepsilon \leqslant 7$ & $\% r \cdot: 10$ & Soybean فول صويا \\
\hline $90 \mathrm{r}$ & $\%$ ro: ro & Sunflower عباد الثمس \\
\hline- & $\% \varepsilon$. & Moringa Oleifera \\
\hline 119. & $\% \leq \neg: \mu \wedge$ & Rapeseed \\
\hline 090. & $\% ч \cdot:$ r. & زيت النخيل Palm oil \\
\hline 1.09 & $\% 00: \leq 0$ & Peanut oil زيت الفول السودانى \\
\hline IVT & $\% 乞 \wedge$ & الذره Corn (Germ) \\
\hline mo & $\%$ Yo: 11 & Cotton seed بذر القطن \\
\hline 1111 & $\% 0 \cdot: \leq 0$ & Jojoba جوجوبا \\
\hline
\end{tabular}

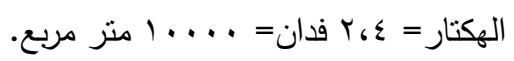

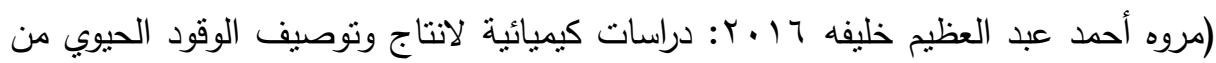
الخروع باستخدام التكسير الحرارى، رسالة ماجيسنير غير منشورة، كلية العلوم، جامعة حلوان)

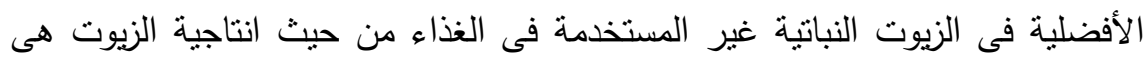

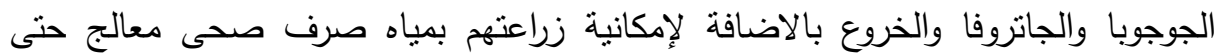

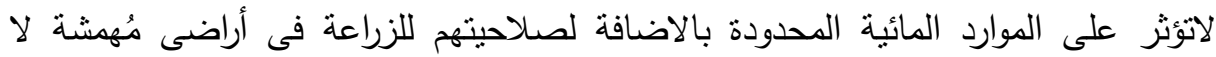

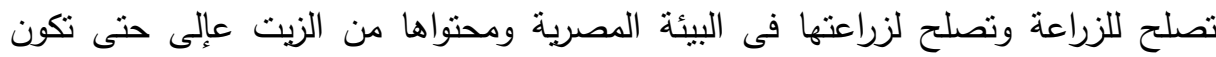
تكلفتها مناسبة وافضل النباتات الغير صالحة للأكل هى الجوجوبا والجاتروفا والخروع، ويتم إجراء عملية كيميائية كالأسترة أو التكسير الحرارى للزيوت النباتية الغير غذائية للحصول على الئي الوقود الحيوي وبالحصول على الوقود الحيوي سواء البيوديزل أو البيوجازولين يمكن استخدامهم 
فى المحركات بدون التأثير على المحركات بالاضافة لأن الانبعاثات أقل مقارنة بالبنزين والسولار كما هو موضح كالتالي:

\begin{tabular}{|c|c|c|c|}
\hline بيوديزل الخروع & بيوديزل الجوجويا & بيوديزل الجاتروفا & الخاصية \\
\hline 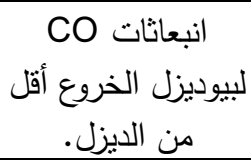 & 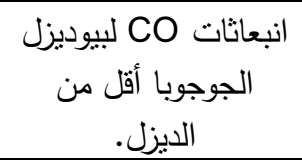 & 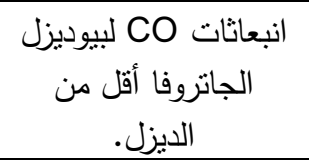 & إلكبعاثات أكاسيد \\
\hline 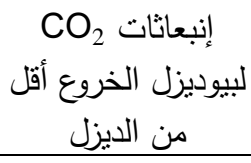 & 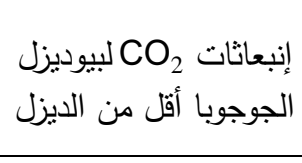 & 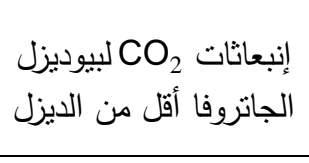 & الكباثات ثانى أكسيد \\
\hline بيوديزل الخروع أقل & بيوديزل الجوجوبا أقل & بيوديزل الجانروفا اعلى الديزل التقلى & $\begin{array}{c}\text { النبعاثات أكاسيد } \\
\text { النيتروجين (NOx) }\end{array}$ \\
\hline بيوديزل الخروع أقل & بيوديزل الجوجوبا أقل & بيوديزل الجاتروفا أقل & $\begin{array}{l}\text { الهيدروكربونات } \\
\text { إنبعانات }\end{array}$ \\
\hline
\end{tabular}

\section{هروض التواسمة}

من أجل تفسير إثكالية البحث ومحاولة الإجابة عن الأسئلة المطروحة يمكن صياغة

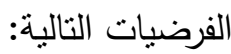

1-يوجد علاقة معنوية ذات دلالة إحصائية بين إستخدام الزيوت النبانية الغير مستخدمة فى الغذاء لإنتاج الوقود الحيوي وحدوث أثز اقتصادي إيجابى. r-يوجد علاقة طردية بين زيادة الإعتماد على الوقود الحيوي وإنخفاض الإنبعاثات والملوثات.

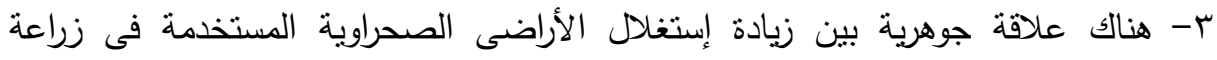
نباتات غير مستخدمة فى الغذاء وخلق فرص عمل جديدة.

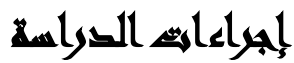

تم تصميم إستمارة إستقصاء جُمعت بالمقابلة وتضمنت العديد من الاسئلة لقياس إتجاهات العينة تجاه متغيرات الدراسة ولتصميم هذا الإستقصاء فقد قامت الباحثة بالإطلاع على العديد من الدراسات السابقة فى مجال موضوع الدراسة ومن خلالها تم إعداد إستمارة إستقصاء مبدئية وقامت بعرضها على بعض من السادة المحكمين وتعديلها وفق توجيهاتهم.

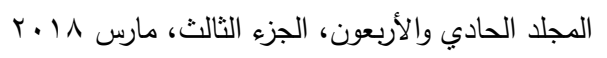


تم عمل دراسة مبئية خلال فترة الدراسة النظرية استمرت عامين من ع ا.ب حتى

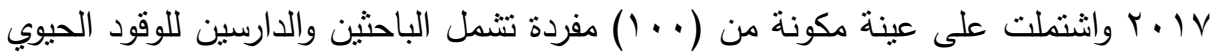
والبيئة ومجال الطاقة المتجددة وباحثين زراعين، وقد توصلت الباحثة إلى الآتي:• يوجد علاقة معنوية ذات دلالة إحصائية بين إستخدام الزيوت النباتية لإنتاج الوقود الحيوي فى مصر وحدوث أثز اقتصادي إيجابى. • يوجد علاقة طردية بين زيادة الإعتماد على الوقود الحيوي وإنخفاض الإنبعاثات والملوثات

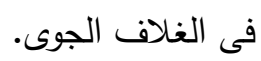

• يوجد علاقة جوهرية بين زيادة إستخلال الأراضى الصحراوية المستخدمة فى زراعة نباتات غير مستخدمة فى الغذاء وخلق فرص عمل جديدة. باستخدام الحاسب الآلى بيرنامج حزم البرامج الإحصائية SPSS Ver.20 لتحليل الييانات التي تم الحصول عليها من خلال قائمة الاستقصاء. قياس ثبات استمارة الاستقصاء:

جدول( ): معاملات الثبات لمتغيرات الدراسة باستخدام "معامل كرونباخ ألفا"

\begin{tabular}{|c|c|c|}
\hline معامل a & عدد العبارات & المتغير \\
\hline$\cdot, \wedge 9 \wedge$ & $\wedge$ & 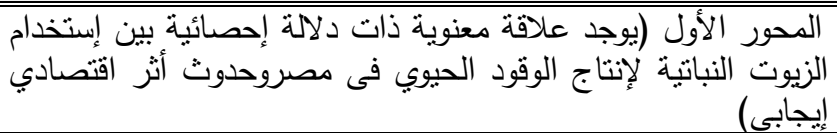 \\
\hline$\cdot, 0 \cdot V$ & 0 & 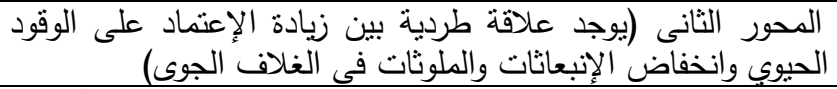 \\
\hline$\cdot, 9 \cdot 9$ & 1 & 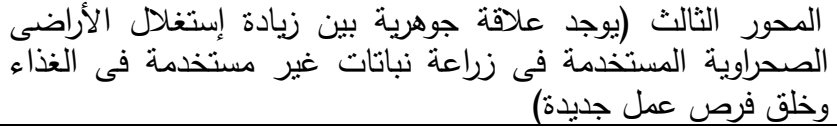 \\
\hline .,Aqr & 19 & إجمالى الإسنتيان \\
\hline
\end{tabular}

يقصد بالثبات أنه لو أعيد توزيع الاستمارات على نفس عينة الدراسة وفى نفس ظروف التطبيق الأول نحصل على نفس الاستجابات، أو استجابات قريبة من النطبيق الأول، وقد قام الأن

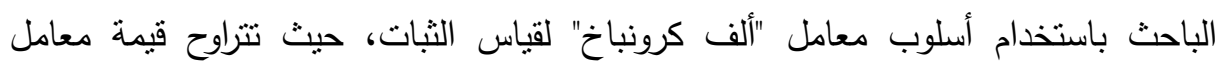
"ألفا"بين صفر ، وواحد، وكلما اقتربت قيمة المعامل من الواحد الصحيح دل على وجود ثنات

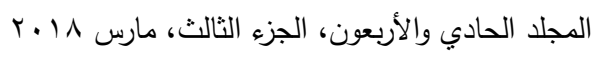


قوى جداً، ولا نوجد قيمة ثابتة يمكن الاعتماد عليها في قياس الثبات في جميع الدراسات، إلا أنه يعتمد قبول القيمة حسب توطن ظاهرة القياس في مجتمع الدراسة وعدد العبارات التي تقيس الظاهرة البحثية ويعتمد عليها الباحث في قبول درجة الثبات. يبين الجدول السابق أن قيم معاملات الثبات جميعها قيم مقبولة حيث بلغت قيم فئه معامل

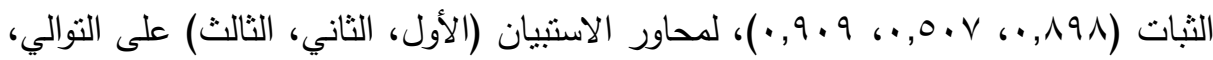

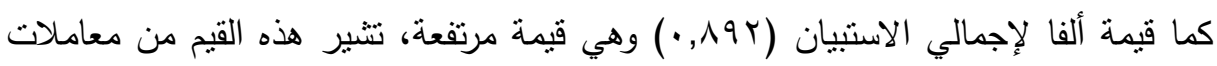
الثبات إلى صلاحية العبارات وإمكانية الاعتماد على نتائجها والوثوق بها. صدق الإتساق الااخلي للاستبيان: تم حساب معاملات ارتباط كل بعد من محاور الاستبيان بالدرجة الكلية للاسنبيان والتي نتجت عن تطبيق الاستبيان على عينة مبدئية، وقامت الباحثة بحساب صدق الإتساق الداخلي ومعامل الارتباط المصحح كالآتي: جدول(ץ): صدق الاتساق الداخلي لمحاور الاستبيان

\begin{tabular}{|c|c|c|c|}
\hline معامل الارتباط & إجمالي الاستبيان & \multicolumn{2}{|c|}{ محاور الاستبيان } \\
\hline \multirow{2}{*}{$\cdot, 9 \leq \varepsilon$} & $\left({ }^{* * *}\right) \cdot, \wedge 9 \leq$ & معامل ارتباط بيرسون & \multirow{2}{*}{ المحور الأول } \\
\hline & $\cdot, \cdots 1$ & الدلالة المعنوية & \\
\hline \multirow{2}{*}{$\cdot, 0 \ldots$} & ("*) & معامل ارتباط بيرسون & \multirow{2}{*}{ المحور الثانى } \\
\hline & $\cdot, \cdots 1$ & الدلالة المعنوية & \\
\hline \multirow{2}{*}{$\cdot, \wedge \vee \mu$} & $(* *),, \vee \vee 0$ & معامل ارتباط بيرسون & \multirow{2}{*}{ المحور الثالث } \\
\hline & $\cdot, \cdots 1$ & الدلالة المعنوية & \\
\hline
\end{tabular}

من جدول صدق الاتساق الداخلي السابق لمحاور الاستبيان نجد أن معامل الارتباط بين

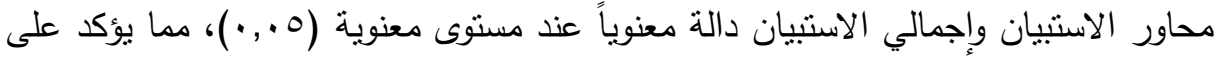

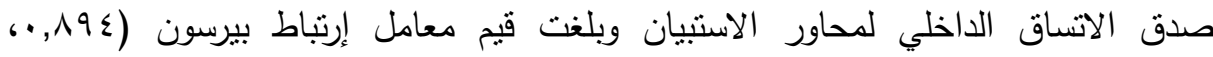

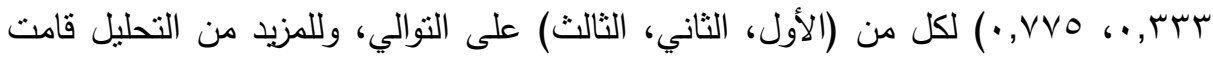

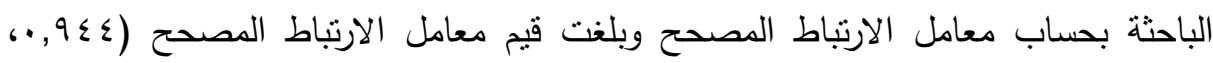

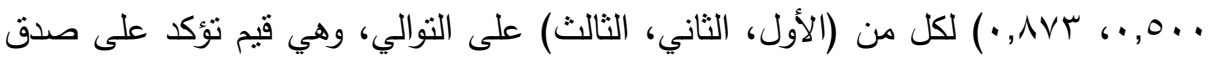

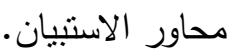


مجلة العلوم البيئية

معهز الدراسات والبحوث البيئية - جامعة عين شمس لهن

\section{نمائي التواسلة}

الفرض الأول: يوجد علاقة معنوية ذات دلالة إحصائية بين استخدام الزيوت النباتية لإنتاج

الوقود الحيوي فى مصر وحدوث أثز اقتصادي إيجابي.

جدول(ץ): نتائج الإحصاء الوصفي لعبارات المحور الأول

\begin{tabular}{|c|c|c|c|c|}
\hline الترتيب & 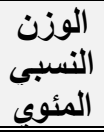 & 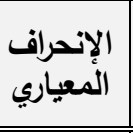 & المسابي & العبارات \\
\hline r & $q \cdot, r$ & •,07 & $\{, 01$ & 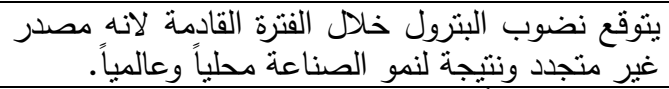 \\
\hline 1 & 97 & •, & $\varepsilon, \wedge$ & 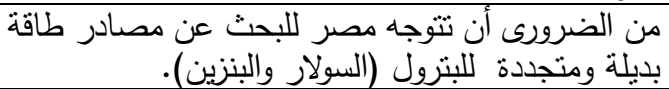 \\
\hline 0 & $\Lambda r, \varepsilon$ & , ^9 & $\varepsilon, \mid \vee$ & للستبرلار والوقود الحيوين أحد مصادر الطاقة المتجددة (بديل \\
\hline 7 & $\Lambda \cdot, \wedge$ & $1, \cdot 1$ & $\varepsilon, \cdot \varepsilon$ & 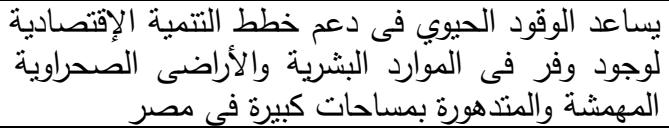 \\
\hline$r$ & $\Lambda \uparrow, \uparrow$ & $\Lambda$ & זוז & 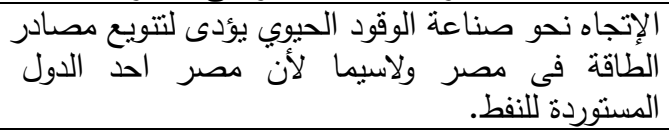 \\
\hline$\varepsilon$ & $\Lambda \neg, r$. & $\cdot, 9$. & $\varepsilon, \Gamma$ & 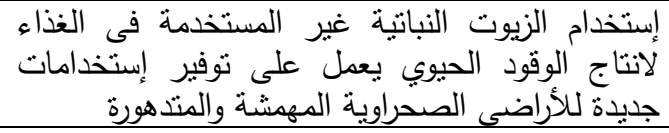 \\
\hline V & $\Lambda_{\cdot}, \ldots$ & $1,1 \varepsilon$ & $\varepsilon$ & 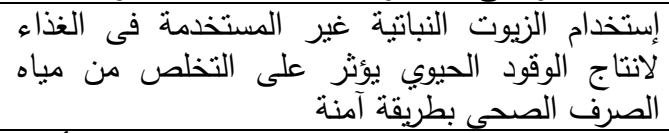 \\
\hline$\Lambda$ & $v_{r}, \ldots$ & $1, r r$ & $r, 70$ & 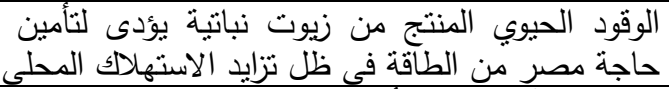 \\
\hline الأول & $\Lambda, T\rangle$ & $\cdot, 9 \mathrm{~V}$ & $\varepsilon, \bullet \wedge$ & الزيوت النباتية فى يوإنتاج الثز اقود الحيوي فادي مصر إستخدام \\
\hline
\end{tabular}

يتبين من الجدول السابق لوصف عبارات المحور الأول: يوجد أثر اقتصادي ناتج عن

إستخدام الزيوت النباتية فى إنتاج الوقود الحيوي فى مصر أن المتوسط قد بلغ (1 •, ــ) بوزن

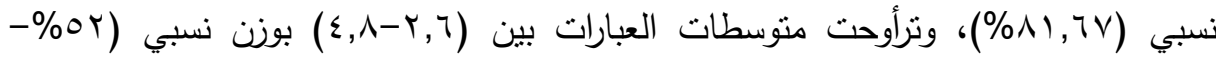
94\% نثير تللك النسب إلى موافقة عينة الدراسة على عبارات المحور الأول: يوجد أثر 
اقتصادي ناتج عن إستخدام الزيوت النباتية فى إنتاج الوقود الحيوي فى مصر، وكان ترتيب

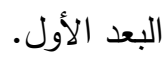

مما سبق ثبت صحة الفرض الأول: يوجد علاقة معنوية ذات دلالة إحصائية بين إستخدام الزيوت النبانية لإنتاج الوقود الحيوي فى مصروحدوث أثر اقتصادي إيجابى.

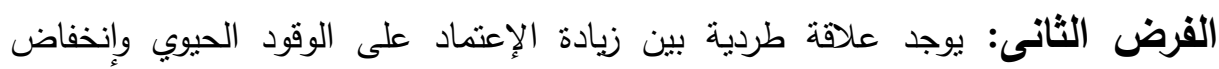

$$
\text { الإنبعاثات والملوثات فى الغلاف الجوى. }
$$

جدول(ء): نتائج الإحصاء الوصفي لعبارات المحور الثنانى

\begin{tabular}{|c|c|c|c|c|}
\hline الترتيب & الوزلن المئوي & الإِعِياري & الحستوسطي & العبارات \\
\hline 1 & $\Lambda 9, r$ & •, 17 & $\{, \leqslant 7$ & 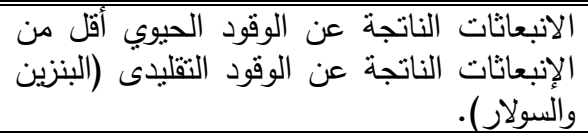 \\
\hline r & $\wedge r, \wedge$ & $\cdot, \wedge$. & $\{, 19$ & 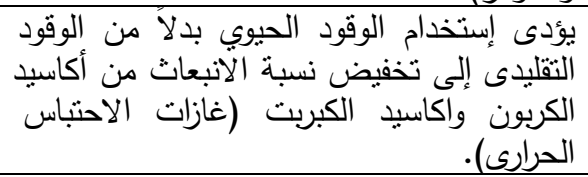 \\
\hline r & $v_{0,7}$ & $\cdot, \wedge \varepsilon$ & $r, \nu \wedge$ & 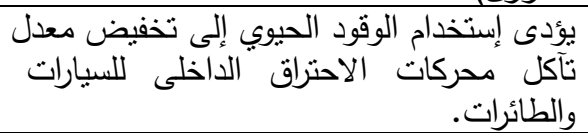 \\
\hline$\varepsilon$ & 01 & $\cdot, V T$ & $r, q$. & البيؤثرجى إستخدام الوقود الحيوي سلباً على التتوع \\
\hline r & גז,^ & $\cdot$, Vo & $\{, 19$ & التتوثية إستخدام الوقود الحيوي إيجابياً على خطط \\
\hline الثالث & $\vee \wedge, \cdot \wedge$ & $\cdot, \mathrm{\vee} \wedge$ & $r, q$. & 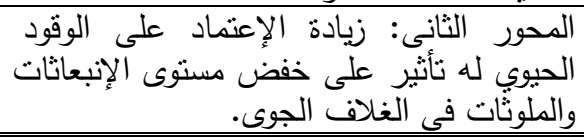 \\
\hline
\end{tabular}

يتبين من الجدول السابق أن المتوسط العام للمحور الثانى: زيادة الإعتماد على الوقود

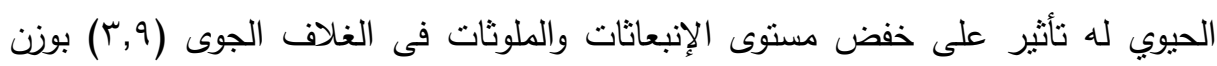

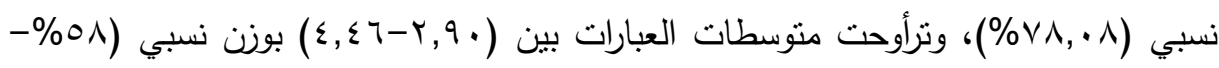

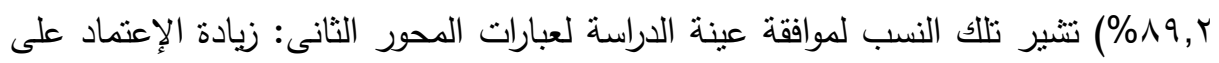
الوقود الحيوي له تأثنر على خفض مسنوى الإنبعاثات والملوثات فى الغلاف الجوى وكان ترنيب البعد الثالث. 
مجلة العلوم البيئية

معهز الدراسات والبحوث البيئية - جامعة عين شمس لهن

مما سبق ثبت صحة الفرض الثانى: يوجد علاقة طردية بين زيادة الإعتماد على الوقود

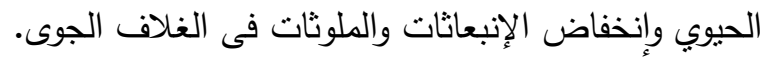

الفرض الثالث: يوجد علاقة جوهرية بين زيادة إستغلال الأراضى الصحراوية المستخدمة فى

زراعة نباتات غير مستخدمة فى الغذاء وخلق فرص عمل جديدة.

جدول(ه): نتائج الإحصاء الوصفي لعبارات المحور الثالث

\begin{tabular}{|c|c|c|c|c|}
\hline الترتيب & 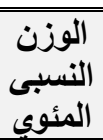 & المعياري & المستوسط & العبارات \\
\hline r & $\vee १, \wedge$ & $1, .9$ & $r, q 9$ & 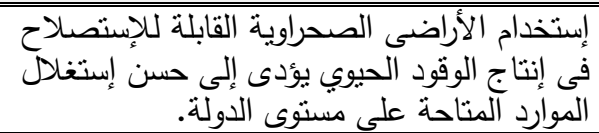 \\
\hline$r$ & $\vee q, \varepsilon$ & $1, .0$ & r,qv & 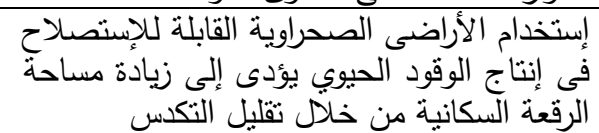 \\
\hline$\varepsilon$ & $\vee \wedge, 7$ & 1,17 & $r, 9 \Gamma$ & 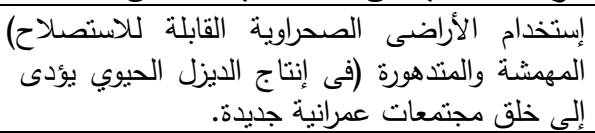 \\
\hline$\varepsilon$ & $V 4, \tau$ & $1, .7$ & r,Ar & 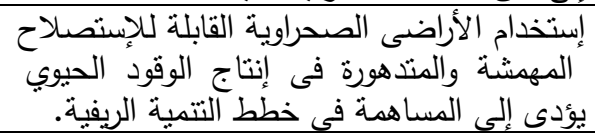 \\
\hline$\varepsilon$ & $\vee \wedge, \uparrow$ & $1,1$. & r,qr & 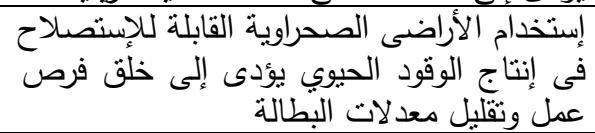 \\
\hline 1 & ^. & 1,17 & $\varepsilon, \ldots$ & 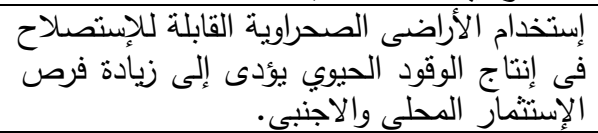 \\
\hline الثانى & $\vee \wedge, \wedge \mu$ & 1,1 . & $r, q \leq$ & 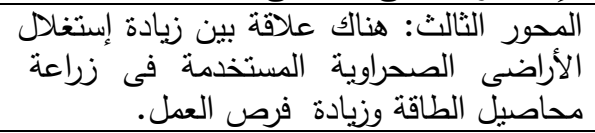 \\
\hline
\end{tabular}

ينتين من الجدول السابق أن المنوسط العام للححور الثالث: هنالك علاقة بين زيادة

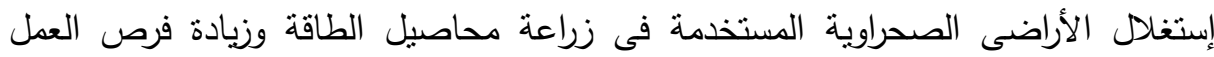

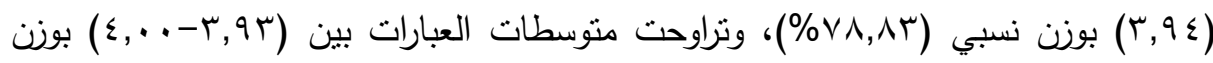

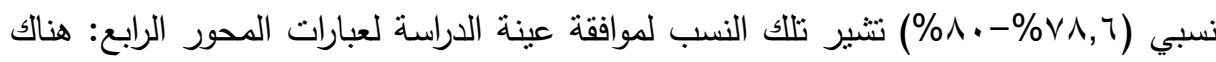


علاقة بين زيادة إستغلال الأراضى الصحراوية المستخدمة فى زراعة محاصيل الطاقة وزيادة فرص العمل وكان ترتيب البعد الثالث.

مما سبق ثبت صحة الفرض الثالث: يوجد علاقة جوهرية بين زيادة إستغلال الأراضى لبكى

الصحراوية المستخدمة فى زراعة نباتات غير مستخدمة فى الغذاء وخلق فرص عمل جديدة.

بالاضافة لما سبق هناك ابحاث تم إجراءها لمقارنة بين خصائص الوقود الحيوي والوقود

التقليدى وتوصلت هذه الدراسات إلى أن خصائص الوقود الحيوي تتماثل مع الوقود التقليدى وأفضل منه فى بعض الخصائص وهذا ما يتبين من خلال الجدول التالي:

جدول(؟): مقارنة بين خصائص بيوديزل الجوجوبا والديزل النفطى (السولار)

\begin{tabular}{|c|c|c|}
\hline الديزل & بيوديزل الجوجويا & الخصائص \\
\hline$\Lambda \wedge, \cdot 1$ & AV & ن ل نسبة الكربون (C \%) \\
\hline $11, \wedge r$ & $\pi$ & نسبة الهيدروجين (H \%) \\
\hline$\cdot, \wedge \mathrm{T}$ & $\cdot, \wedge \sum Y \mid$ & الكثافة (جم/سمَ) Density@60/60F (gm/cc) \\
\hline$\varepsilon, 0$ & $\varepsilon, \vee \wedge$ & اللزوجة اللز \\
\hline$\sum \Gamma, 1$ & $\sum 7$ & القيمة الحرارية Calorific value MJ/ Kg \\
\hline$\leqslant 9$ & $7 \varepsilon$ & Cetane no رقم السيتان \\
\hline$\cdot, \cdot, 1$ & $\cdot, \ldots 1 \varepsilon$ & Ash content \% wt \% نسبة الثوائب \\
\hline$\cdot, 10$ & $\cdot, \cdot, \varepsilon$ & Water Content mg/ kg محتوى الماء \\
\hline$\cdot, 1$ & $\cdot, 1$ & نarbon residue \%wt نسبة شوائب كربونية \\
\hline$\cdot, \cdot Y$ &., .11 & نسبة الرواسب Sediment \% wt \\
\hline 1,0 & لايوجد & Sulpher content\% محتوى الكبربت \\
\hline
\end{tabular}

جدول (V): مقارنة بين خصائص بيوجازولين الجوجوبا والجازولين (البنزين)

\begin{tabular}{|c|c|c|}
\hline بنزين ، 9 & بيوجازولين & الخصائص \\
\hline.,$\times 9.0$ & $\cdot, \wedge \cdot 9$ & كثنافة Density@15oC \\
\hline - & $\cdot, \Lambda \cdot \Lambda \mathrm{Y}$ & كنافة Density@23oC \\
\hline - & $\cdot, 9$ & اللزوجة الكينماتيكية C kinematic Viscosity @ \\
\hline 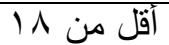 & 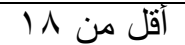 & Flash Point (Closed Cup)C نقطة الوميض \\
\hline$\sum Y, 0$ & $\sum 7,19$ & Calorific value MJ/ Kg القيمة الحرارية \\
\hline لايوجد الايد & لايوجد & norganic Acids mgKOH /gm أحماض غير عضوية \\
\hline 9. & 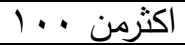 & رقم الأوكتان Octane No \\
\hline لا يوجد & لايوجد الايد & Water Content mg/ kg محتوى الماء \\
\hline 191 & ᄉT & F.B.P C نقطة الغليان النهائية \\
\hline
\end{tabular}


مجلة العلوم البيئية

معهد الدراسات والبحوث البيئية - جامعة عين شمس ليه

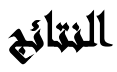

• يتوافر لدى مصر مصادر وفيرة لإنتاج وقود حيوى متمنلة فى الأراضى الغير المستغلة

ومياه صرف صحى والأيدى العاملة وكوادر مؤهلة.

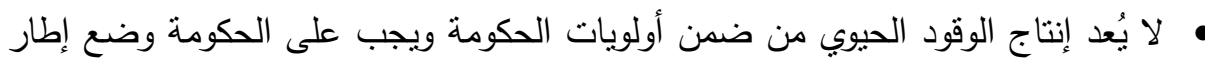

تشريعى سليم وإجراءات صارمة لاعم إنتاجه بطريقة مستدامة.

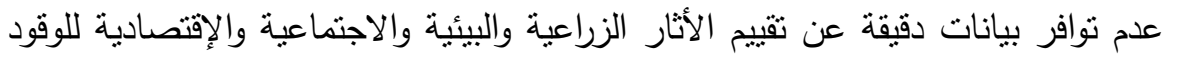

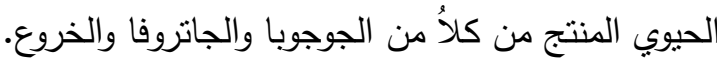

إنتاج الوقود الحيوي فى مصر بتمنل فى الأبحاث العلمية التى تؤكد إمكانية انتاجة

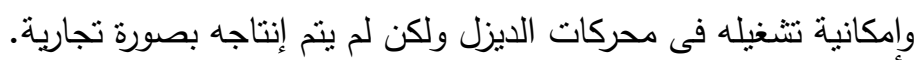

\section{التموسيايت}

• وضع مجال الطاقة المتجددة ضمن أولويات الاستثمار والانفاق الحكومى. • على الدولة القيام بوضع إطار تشريعى سليم وإجراءات لدعم برامج الطاقة المتجددة ليتم إنجازها فى الوقت المحدد لها. • إنشاء مراكز بحثية فى الطاقات المتجددة لتأهيل كوادر ومهارات ودعم مشروعات الطاقة

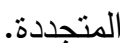
• دعم الدولة لمشروعات الوقود الحيوي من خلال منح امنيازات للمشروعات المنتجة للوقود

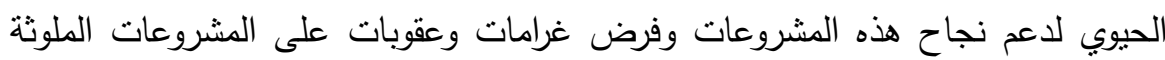
للبيئة. • يجب أن يتم تصميم مشاريع الوقود الحيوي وتشغيلها من قبل الدولة ويشارك فيها جميع أصحاب المصلحة. 


\section{المرالمب}

أمجد قاسم: "أربعة أجيال من الوقود الحيوي والتحديات لا تزال ضخمة"، مجلة القافلة، عدد ؟

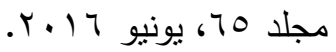

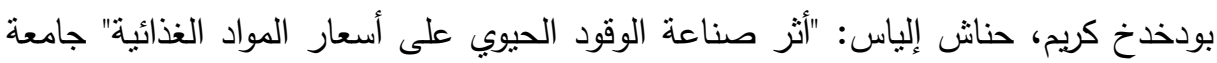

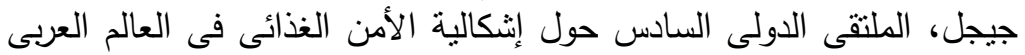

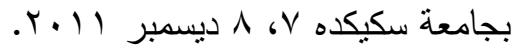

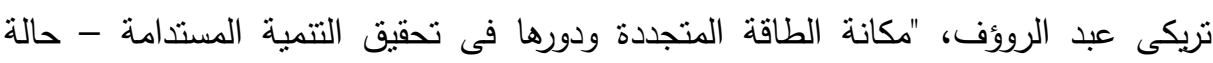
الجزائر"، ماجيستير، جامعة الجزائر كلية العلوم الاقتصادية، العائة العلوم الاقتصادية التهاية

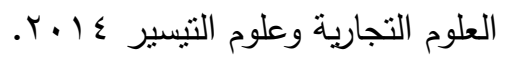

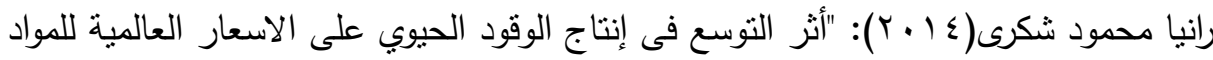

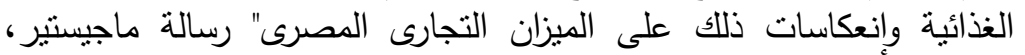
جامعة القأهرة كلية الاقتصاد والعلوم العاك السياسية

عقيل عبد محمد و م.م. محمد راضى: جعفر، الوقود الحيوي السائل بديل النفط مفهومة وأثناره

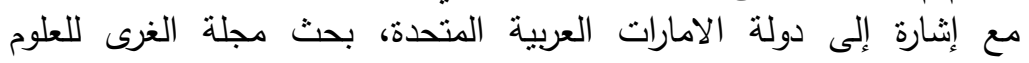

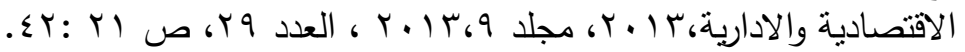

طالبى ومحمد ساحل: "أهمية الطاقة المتجددة فى حماية البيئة لأجل التتمية المستدامة -

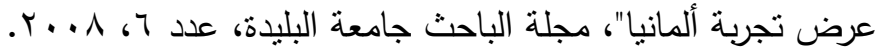

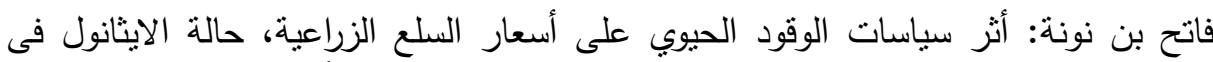

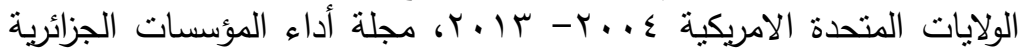

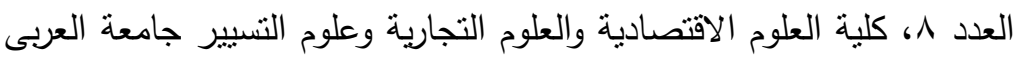

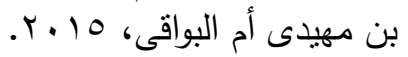

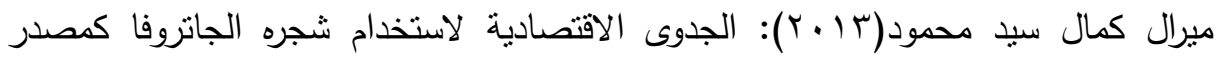

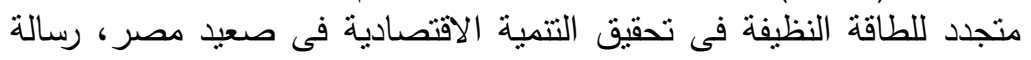

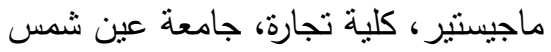

عبد الباسط عودة إبراهيم، التمور مصدر بديل لانتاج الوقود الحيوي (الوقود النباتى)، مقالة

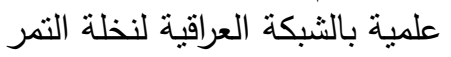

http://www.iraqi-datepalms.net/Web/WebContent.aspx?id=6

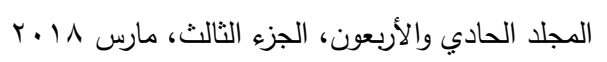




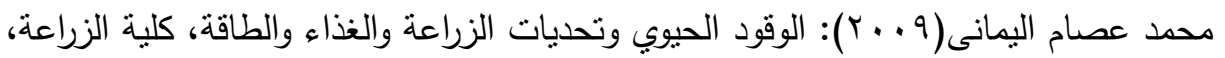

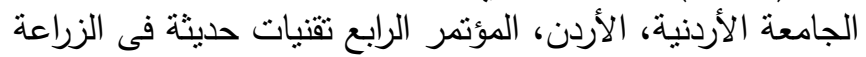

محمد سرحة وجمال مصرى(· ( †): الوقود الحيوي البيوفيول والمؤثرات البيئية الناتجة عن استخدامه، المجموعة المصرية الهندسية للأبحاث البيئية

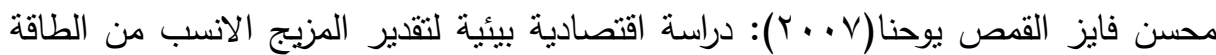

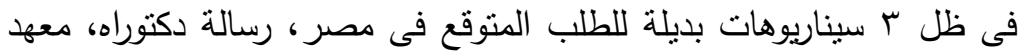
الدراسات والبحوث البيئية، جامعة عين شمس بلئ

محمد أحمد السيد خليل(9 . ب): "أزمة الطاقة والتحدى القادم: دراسة استراتيجية بيئية هندسية"، دار الفكر العربى، الطبعة الأولى الطى

Amit Kumar Jain, Amit Suhane (2012): Review article: Research approach \& prospects of non edible vegetable oil as a potential resource for biolubricant - A review, Advanced Engineering and Applied Sciences: An International Journal, pp. 23:32.

Atabani, A. E. \& Silitonga, A. S. (2013): "Non-edible vegetable oils: A critical evaluation of oil extraction, fatty acid compositions, biodiesel production, characteristics, engine performance and emissions production", Renewable and Sustainable Energy Reviews, Volume 18, Pp. 211-245.

David Pimental (2008): "Biofuels, Solar and winds as renewable energy systems", Springer.

Khandelwal Shikha \& Chauhan. Y. Rita (2012): "Biodiesel production from non-edible oils: A review", Journal of Chemical and Pharmaceutical Research, vol. (4), Pp. 4219-4230.

Radwan, M. S. \& Osayed Abu-El-yazeed (2012): An Investigation on Abnormal Combustion, Emissions and Performance of Novel Jojoba BioGasoline and Its Blends with Gasoline in a SparkIgnition Engine, SAE International journal.

Radwan, M.; Osayed, Abu-Elyazeed \& Morsy, M. E. (2014): On the Ignition Delay of Jojoba Bio-Diesel and Its Blends with Gas Oil , SAE International journal. 


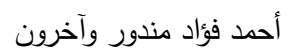

\title{
MEASURING THE ECONOMIC AND \\ ENVIRONMENTAL REVENUES TO ENLARGE IN \\ THE PRODUCTION OF NON EDIBLE VEGETABLE \\ OILS TO PRODUCE BIO-FUELS IN EGYPT
}

\author{
Mandour, A. F. ${ }^{(1)}$; Atay, Y. A. ${ }^{(2)}$ and Ali, Rehab, A. ${ }^{(2)}$ \\ 1) Faculty of Commerce, Ain Shams University 2) Faculty of \\ Engineering in Mattaria, Helwan University
}

[17]

\begin{abstract}
The study aimed at measuring the economic and environmental revenue for the expansion of the production of non-edible vegetable oils for the purpose of producing biofuels. Research and studies are in Egypt to produce bio-fuel as an alternative to diesel and gasoline but have not yet been produced for commercial purposes. Energy is a key element for economic development, however, the traditional form of energy is fossil fuel energy. There are several reasons to search for alternative sources of traditional energy: (Economic objective); concern about climate change (environmental goal); low cost of renewable energies (economic target), and support for agricultural producers (agricultural and economic objective).

As a result of many reasons, the most important of which is the expected oil depletion by the end of the 21 st century, the rise in oil prices and the negative effects of toxic emissions from fossil fuels on the environment and climate. Therefore, it was necessary to search for alternative renewable sources such as solar, wind and bioenergy. The production of biofuels is related to the agricultural sector. In order to benefit from the enormous potential that it enjoys in terms of abundance of untapped desert lands and desolate land and water resources for the production of biofuel as a source of renewable energy has been studying the energy crops suitable for the production of biofuel Three plants were selected to be suitable for agriculture in the Egyptian
\end{abstract}

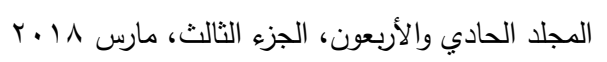




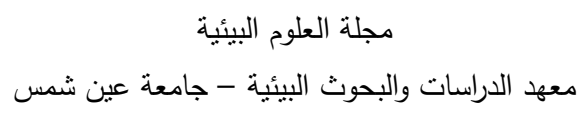

environment and suitable for agriculture in desert and desert lands and sewage water. This is because there is no conflict between food and energy. The environmental impact of energy crops and the effect of biofuel production on energy crops on both land use change, On water, on agricultural soils, on biological diversity, study of the economic impact and production costs of biofuels (biogasoline and biodiesel) in the two ways of cracking and the method of extraction from the cost of growing energy crops until the stage of obtaining biogasoline and biodiesel.

The study reached several results: Biofuel production is not a priority for the government and the government must establish a sound legislative framework and strict procedures to support its production in a sustainable manner. Egypt has abundant sources of bio-fuel production represented in land, water, labor and qualified cadres. Lack of accurate data on the assessment of the agricultural, environmental, social and economic impacts of bio-fuels produced from both Jojoba, Jatropha and Al-Kharoua. There are no success stories on the production of bio-fuels from the non edible vegetable oils of Jojoba, Jatropha and castor plants. Therefore, the government should interact with stakeholders and companies to disseminate the right information to make good decisions.

Key words: Renewable Energy, Biofuel, Sustainable Development. 